\title{
A Unified Framework for Assessment and Application of Ecological Thresholds
}

\author{
D. D. Briske, ${ }^{1}$ S. D. Fublendorf, ${ }^{2}$ and F. E. Smeins ${ }^{1}$ \\ Authors are from the ${ }^{1}$ Department of Rangeland Ecology and Management, Texas A $\leftrightarrow$ M University, 2126 TAMU, \\ College Station, TX 77843; and ${ }^{2}$ Department of Plant and Soil Sciences, Oklahoma State University, Stillwater, OK 74078-6028.
}

\begin{abstract}
The goal of this synthesis is to initiate development of a unified framework for threshold assessment that is able to link ecological theory and processes with management knowledge and application. Specific objectives include the investigation of threshold mechanisms, elaboration of threshold components, introduction of threshold categories and trajectories, and presentation of an operational definition of ecological thresholds. A greater understanding of ecological thresholds is essential because they have become a focal point within the state-and-transition framework and their occurrence has critical consequences for land management. Threshold occurrence may be best interpreted as a switch from the dominance of negative feedbacks that maintain ecosystem resilience to the dominance of positive feedbacks that degrade resilience and promote the development of post-threshold states on individual ecological sites. Threshold categories have been identified to serve as ecological benchmarks to describe the extent of threshold progression and increase insight into feedback mechanisms that determine threshold reversibility. Threshold trajectories describe the developmental pathway that post-threshold states may follow once a threshold has been exceeded. These trajectories may produce a continuum of potential post-threshold states, but the majority of them may be organized into four broad states. This framework lends itself to management application by providing an operational definition of thresholds that is based on a probabilistic interpretation. Probabilities associated with 1) the occurrence of triggers that initiate threshold progression, 2) the trajectory of post-threshold states, and 3) threshold reversibility will provide an operational procedure for threshold assessment and application. If thresholds are to play a central role in rangeland ecology and management, then the rangeland profession must accept responsibility for their conceptual development, ecological validity, and managerial effectiveness.
\end{abstract}

\section{Resumen}

La meta de esta síntesis es iniciar el desarrollo de un marco teórico unificado para la evaluación de los umbrales que sea capaz de relacionar la teoría ecológica y procesos con el conocimiento de manejo y su aplicación. Los objetivos específicos incluyen la investigación de los mecanismos de los umbrales, la elaboración de los componentes de los umbrales, la introducción de categorías y trayectorias de los umbrales y la presentación de una definición operativa de los umbrales ecológicos. Un mayor entendimiento de los umbrales ecológicos es esencial porque ellos han venido a ser el punto focal dentro del marco de la teoría de estados estables y transición, y su ocurrencia tiene consecuencias criticas para el manejo de los pastizales. La ocurrencia de umbrales puede ser mejor interpretada como un cambio de la dominancia de reacciones negativas que mantienen la resilencia del ecosistema a la dominancia de reacciones positivas que degradan la resilencia y promueven el desarrollo de estados posteriores al umbral en sitios ecológicos individuales. Las categorías de umbrales han sido identificadas para servir como puntos de referencia ecológicos para describir la cantidad de progreso del umbral e incrementar la perspicacia dentro de los mecanismos de reacción que determinan la reversibilidad de los umbrales. Las trayectorias de los umbrales describen la vía de desarrollo que los estados post-umbral pueden seguir una vez que el umbral ha sido superado. Estas trayectorias pueden producir un continuo de estados potenciales post-umbrales, pero la mayoría de ellos pueden ser organizados en cuatro amplias categorías. Este marco teórico, por si mismo, es apropiado para la aplicación de manejo al proveer una definición operativa de los umbrales que es basada en una interpretación probabilística. Las probabilidades asociadas con: 1) la ocurrencia de disparadores que inician la progresión de los umbrales, 2) la trayectoria de los estados post-umbrales, y 3) la reversibilidad de los umbrales que proveerá un procedimiento operacional para la evaluación y aplicación de los umbrales. Si los umbrales van a jugar un papel central en la ecología y manejo de pastizales, entonces la profesión de manejo de pastizales debe aceptar la responsabilidad de su desarrollo conceptual, validez ecológica y efectividad de manejo.

Key Words: ecological monitoring, ecological resilience, feedback mechanisms, multiple stable states, regime shifts, stateand-transition models

\section{INTRODUCTION}

State-and-transition models have become widely adopted for vegetation evaluation and management on rangelands (USDA-

Correspondence: D. D. Briske, Dept of Rangeland Ecology and Management, Texas A\&M University, 2126 TAMU, College Station, TX 77843-2126. Email: dbriske@tamu.edu

Manuscript received 30 June 2005; manuscript accepted 29 January 2006.
NRCS 1997; Stringham et al. 2003; Bestelmeyer et al. 2004). They provide a robust framework to evaluate vegetation dynamics by accommodating multiple successional pathways and stable states on individual ecological sites (Bestelmeyer et al. 2003; Stringham et al. 2003; Cingolani et al. 2005). This framework enables rangeland professionals to apply ecological information to various natural resource management objectives and to identify relevant ecological and managerial research 
questions (Westoby et al. 1989; Holling 1996; Bestelmeyer et al. 2004). Ecological thresholds have become a focal point within the state-and-transition framework because they differentiate among the various stable states that may potentially occupy individual ecological sites (Stringham et al. 2003; Walker and Meyers 2004; Briske et al. 2005). Threshold recognition and prediction is also necessary to enable rangeland managers to prevent the occurrence of undesirable states and to promote the occurrence of desirable states (Watson et al. 1996; Bestelmeyer et al. 2003).

Ecological thresholds originated with development of the multiple stable state concept to describe boundaries between alternative stable states that may potentially occur on individual sites (Holling 1973; May 1977). Holling (1973) initially emphasized the importance of determining the possibility that ecosystems may move from one stable domain to another and persist in an altered configuration. However, the threshold concept was not introduced to the rangeland profession until nearly 20 years later when it followed on the heels of the non-equilibrium paradigm (Ellis and Swift 1988) and state-and-transition framework (Westoby et al. 1989). The initial interpretation of thresholds was based on observations that transitions among some stable states were reversed so slowly, if at all, that they constrained rangeland management options (Friedel 1991; Laycock 1991).

Friedel (1991) initially defined thresholds as, "a boundary in time and space between two states that is not reversible on a practical time scale without management intervention." However, this widely used rangeland interpretation is primarily a management construct because it is based on a time frame established by land use objectives, rather than on ecological processes that determine vegetation dynamics (Briske et al. 2005). Stringham and others (2003) have incorporated ecological processes into the threshold concept by indicating that, "thresholds are boundaries in space and time between any and all states, such that one or more of the primary ecological processes has been irreversibly changed and must be actively restored before return to the previous state is possible." This interpretation represents a valuable and necessary advance for the development of ecological thresholds that is based on the concept of ecological resilience. Ecological resilience describes the degree of ecosystem modification that is required before the system begins to reorganize around an alternative set of reinforcing processes (Peterson et al. 1998; Gunderson 2000). However, the rangeland profession has yet to develop an organizational framework and operational interpretation of thresholds for rangeland application (Muradian 2001; Walker and Meyers 2004; Briske et al. 2005).

We contend that ecological thresholds require further evaluation and development to ensure that this pivotal concept is appropriately and effectively incorporated into the rangeland profession (e.g., Lindenmayer and Luck 2005; Briske et al. 2003, 2005). It is evident that thresholds are the result of several potentially interacting components, rather than simple boundaries in time and space (Mayer and Rietkerk 2004; Peters et al. 2004; Briske et al. 2005; Huggett 2005). The inability to satisfactorily, or even partially, answer the following questions emphasizes both the complexity and limited development of the threshold concept (e.g., Huggett 2005; Groffman et al. 2006). What events or triggers initiate threshold development? What ecological mechanisms establish threshold duration and mag- nitude? How can pending thresholds be identified and at what point do thresholds initially become irreversible? Are thresholds similarly expressed in all vegetation types and climatic zones? To what extent do thresholds reflect changes in ecosystem function or health? A limited understanding of threshold complexity and behavior frequently results in their identification after, rather than prior to, their occurrence which minimizes their value to land management.

The overarching goal of this synthesis is to initiate development of a unified framework for threshold assessment that is able to link ecological theory and processes with management knowledge and application. Specific objectives include the investigation of threshold mechanisms, elaboration of threshold components, introduction of threshold categories and trajectories, and presentation of an operational definition of ecological thresholds. We do not envision this framework to provide an immediate solution to threshold assessment and application, but rather to establish a long-term approach that will enable rangeland professionals to organize and refine existing ecological knowledge and management experience for more effective land management. The assembled linkage of potential relationships described within this threshold framework represent a series of hypotheses that can be tested by both simulation and experimental investigations.

\section{THRESHOLD MECHANISMS}

Insight into the ecological processes that contribute to threshold occurrence would greatly increase our ability to interpret and apply this ecological concept. Threshold mechanisms have primarily been interpreted in a theoretical or conceptual framework that is difficult to incorporate into operational procedures for land management (Groffman et al. 2006). Two broad alternative mechanisms of threshold occurrence have been proposed by Beisner and others (2003). In the first mechanism, disturbances are assumed to force stable states across thresholds by modifying biotic structure and interactions within communities (e.g., altered population and competitive dynamics and plant-herbivore interactions) (Beisner et al. 2003) (Fig. 1). The biotic mechanism is the most frequently applied mechanism of threshold occurrence in the rangeland profession (e.g., Westoby et al. 1989; Bestelmeyer et al. 2003; Stringham et al. 2003).

In the second mechanism, thresholds between stable states may be surpassed in response to long-term abiotic changes that modify site characteristics (e.g., climate change, severe soil erosion, water table variation, soil salinization, eutrophication) (e.g., Tausch et al. 1993; Higgins et al. 2002; Folke et al. 2004) (Fig. 1). This abiotic mechanism is less frequently invoked in the rangeland profession because ecological assessments often reference shorter time frames than are required for the modification of abiotic site attributes (i.e., ecological sites are assumed to remain constant). However, many of the thresholds currently observed may partially reflect vegetation responses to previous climatic shifts because vegetation dynamics exhibit a substantial lag (i.e., biological inertia) in response to climatic variation (Davis 1986; Prentice 1986; Nowak et al. 1994). The prolonged lag in vegetation response to climatic variation implies that biotic and abiotic threshold mechanisms need not 


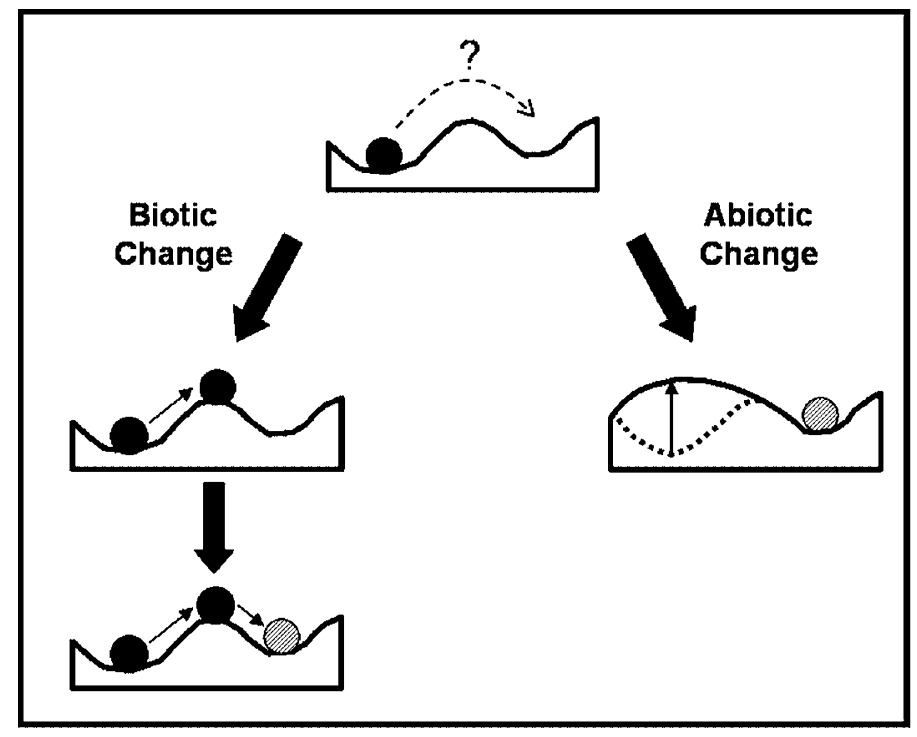

Figure 1. Ball-and-cup diagram illustrating two general mechanisms hypothesized to force pre-threshold states (ball) from basins across hill tops (thresholds) to alternative post-threshold states. On the left, disturbances force a pre-threshold state across a threshold to an alternative state by modifying biotic structure and interactions within an ecosystem without substantive change to abiotic site characteristics. On the right, abiotic environmental modifications alter both the basin and hill top to force the pre-threshold state across a threshold. The dashed line depicts the initial site characteristics and the arrow indicates the direction and magnitude of abiotic site modification. Modified from Beisner et al. (2003) and reproduced with permission of the Ecological Society of America.

be mutually exclusive, but they may often be uncoupled in temporal scale.

Feedbacks describe the ecological processes that reinforce or degrade ecosystem resilience and function (Wilson and Agnew 1992; Whisenant 1999; Gunderson 2000; Bestelmeyer et al. 2003; Mayer and Rietkerk 2004) (Table 1). Negative feedbacks contribute to ecosystem stability by reinforcing resilience and recovery following the occurrence of disturbances while positive feedbacks have the opposite effect of degrading ecosystem resilience and promoting conversion to alternative stable states (Whisenant 1999; Walker and Meyers 2004). The point at which feedbacks switch from a dominance of negative to positive processes will initiate threshold occurrence (Fig. 2). These feedback mechanisms are variously linked to associated threshold components to establish unique threshold characteristics and behaviors (Archer et al. 2001; Scheffer et al. 2001; van de Koppel et al. 2002; Peters et al. 2004).

Threshold definition as a switch from negative to positive feedbacks provides a more specific description of how ecological processes may contribute to threshold occurrence within the "basin of attraction" model (e.g., Peterson et al.1998; Scheffer and Carpenter 2003; Stringham et al. 2003; Mayer and Rietkerk 2004) (Fig. 2). The feedback switch represents the relative strength of negative:positive feedbacks that defines the limits of ecosystem resilience. Negative feedbacks dominate within the basins to maintain ecosystem stability while the strength of negative and positive feedbacks is approximately equal in the hilltops. In cases where positive feedbacks exceed negative feed- backs, the ecosystem is destabilized and an alternative ecosystem may begin to occupy the site. Both biotic and abiotic threshold mechanisms may contribute to the occurrence of a feedback switch, independently or in combination, to initiate thresholds. The feedback switch mechanism of threshold occurrence has been incorporated into the threshold framework presented below.

This framework addresses thresholds at the scale of individual ecological sites because this represents the scale at which most land management agencies have initially chosen to apply them. However, it is becoming increasingly clear that thresholds are often expressed across multiple sites at landscape and regional scales and that critical scale dependencies are often overlooked by both observation and models (Peters et al. 2004; Breshears et al. 2005; van Nes and Scheffer 2005). For example, site specific thresholds are constantly shifting in response to more spatially extensive variables and processes (Groffman et al. 2006), but coarse scale dynamics often have limited ability to explain modifications on local sites. Landscape level thresholds have been hypothesized to occur at the point where coarse scale processes override fine scale processes on individual sites (Peters et al. 2004). The occurrence and behavior of landscape level thresholds poses an important research question for the rangeland profession, but it is not addressed in this synthesis.

\section{THRESHOLD FRAMEWORK}

\section{Threshold Components}

Thresholds represent a broad continuum of transitions among stable states that vary greatly in duration, complexity, and potential for reversibility (Briske et al. 2005). However, most thresholds are likely to possess several critical components, including triggers, structural modifications, functional modifications, and feedback mechanisms. The relative expression and interaction among these components intensifies as thresholds progress through time to produce unique threshold characteristics and behaviors. Greater awareness of these components and their interactions will increase our ability to interpret and apply thresholds on an ecological basis (Table 1).

Triggers. Triggers represent changes in specific biotic or abiotic variables that initiate threshold development. Triggers may be natural or anthropogenic, continuous or discontinuous (i.e., pulsed), additive or multiplicative, and chronic or acute (see previous thresholds mechanisms section). They initiate threshold progression by inducing a discontinuous shift from the dominance of negative to positive ecosystem feedbacks (e.g., feedback switch mechanism). For example, fire may have a dramatic and immediate impact on ecosystem feedbacks while fire suppression would trigger a much more prolonged and delayed effect (Bond and van Wilgen 1996; Briggs et al. 2005). Fire suppression is a widely recognized cause of woody plant encroachment regardless of the associated grazing regime and species composition of herbaceous communities (Fuhlendorf and Smeins 1997; Brown and Archer 1999). However, the reestablishment of frequent fire regimes in communities codominated by grasses and woody plants may not reduce woody plant cover and it may even increase it, if woody species possess the capacity to resprout following fire (Heisler et al. 2004; Briggs et al. 2005). 
Table 1. Glossary outlining a unified framework for threshold assessment and application on individual ecological sites. The glossary is designed to support figure interpretation.

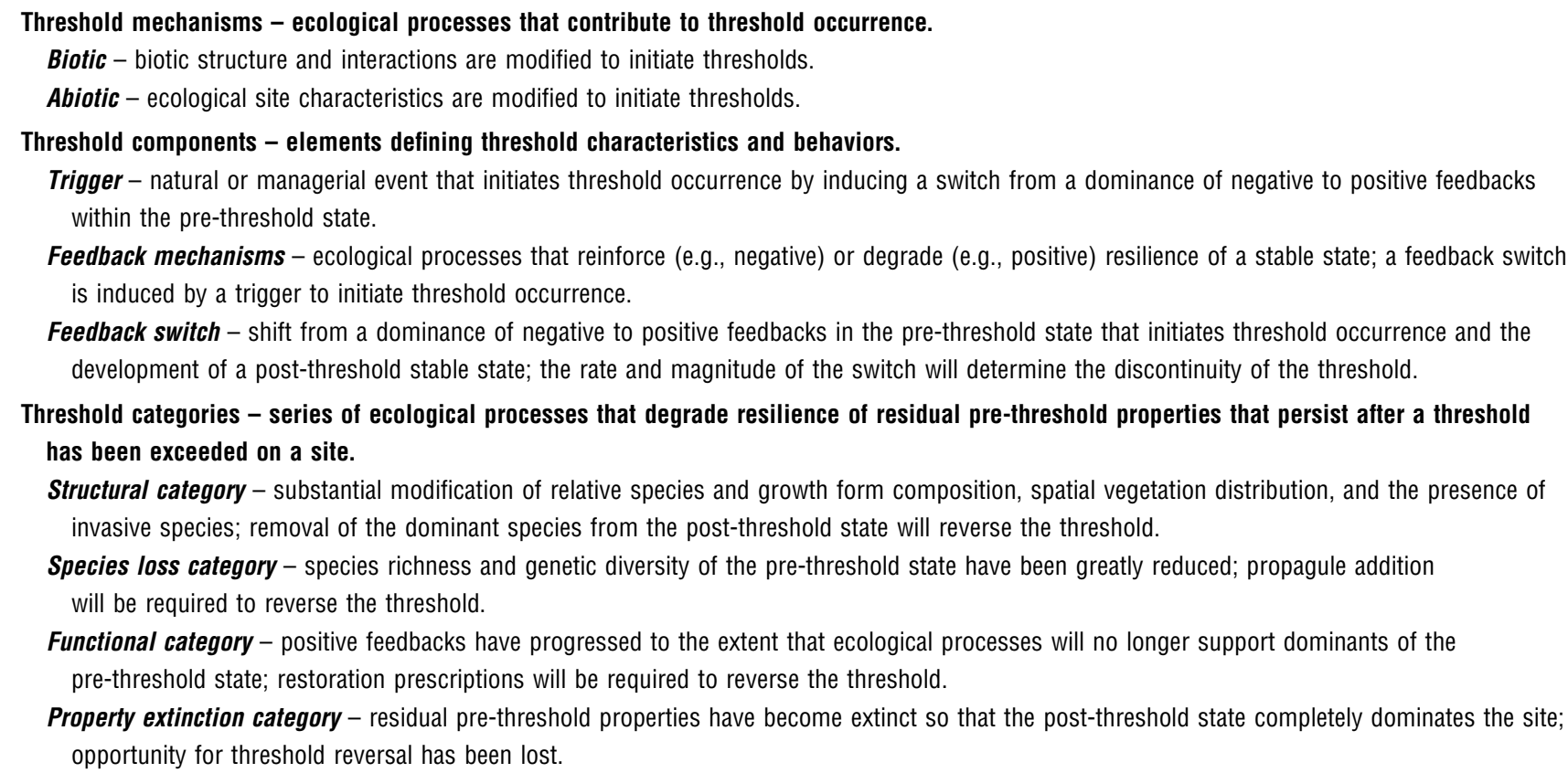

Threshold trajectory - developmental pathway of a post-threshold state after a threshold has been exceeded.

Operational threshold - series of probabilities that determine threshold occurrence, trajectory of the post-threshold state, and threshold reversibility.

Fire may also reinforce the occurrence of undesirable thresholds as in the case of exotic grass invasions, including cheatgrass (Bromus tectorum) in the Intermountain West (D'Antonio and Vitousek 1992; Mack and D'Antonio 1998; Cione et al. 2002). Invasion of exotic grasses increases both the amount and continuity of fine fuel load and fire frequency to reduce the abundance of native perennial grasses and shrubs that are less fire tolerant. Cheatgrass seed that matures and falls to the soil surface escapes fire injury to perpetuate cheatgrass dominance (Mack 1981; Knapp 1996).

Herbivory represents a unique trigger that removes vegetative cover selectively on both spatial and temporal scales. This trigger is associated with the chronic, selective influence of grazing on individual species or species groups compared to the associated triggers of fire and weather extremes that exert a more intermittent and less selective effect on ecosystems feedbacks (Illius and O'Connor 1999). Herbivory represents a continuous, constant trigger in confined, commercial, livestock operations, but it may be much more dynamic in pastoral systems that are subject to large fluctuations in livestock density and movement and in that system may act as a continuous, variable trigger. Intensive, chronic herbivory reduces fine fuel loads and the potential effect of fire induced mortality on woody plants (Briggs et al. 2005).

Weather extremes, including long-term droughts and sequences of wet years, can be categorized as prolonged pulse triggers because they affect ecosystems over extended temporal scales (Watson et al. 1996; Breshears et al. 2005; Fensham et al. 2005). Drought coupled with high temperatures can induce plant mortality and favorable weather conditions can promote seed germination and plant establishment (Bestelmeyer et al.
2004). Episodic establishment of Mitchell grass (Astrebla spp.) (Austin and Williams 1988), black grama (Bouteloua eriopoda) (Bestelmeyer et al. 2004), and various shrubs species (Watson et al. 1997), and the modification of grassland composition in response to seasonal and annual precipitation patterns (Walker 1993; O'Connor and Roux 1995) represent weather-induced variation of vegetation dynamics that may initiate threshold development.

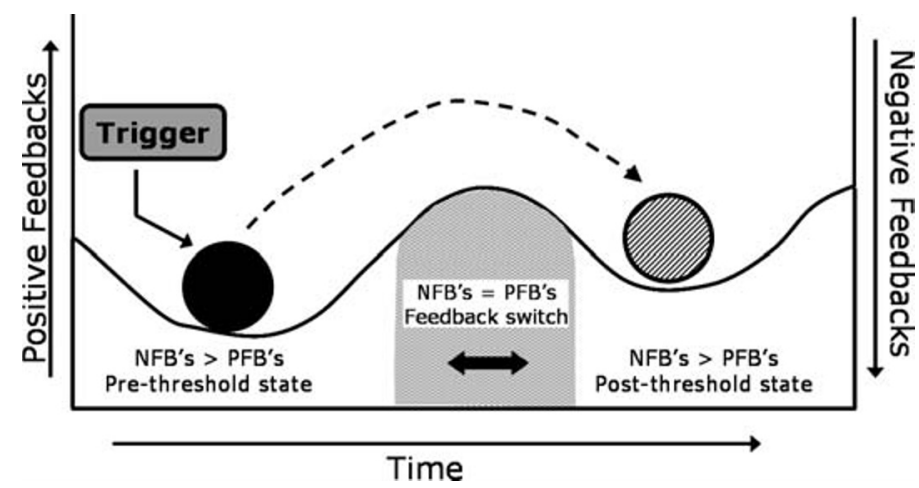

Figure 2. Schematic illustrating threshold occurrence as a feedback switch mechanism (shaded region). Thresholds represent the point at which feedbacks switch from a dominance of negative feedbacks (NFB) that maintain resilience of the pre-threshold state (solid ball) to a dominance of positive feedbacks (PFB) that decrease resilience of the pre-threshold state and enable an alternative post-threshold state (crosshatched ball) to occupy the site. The feedback switch determines the degree of discontinuity associated with threshold initiation. Triggers represent events that initiate the feedback switch to begin threshold progression (see Table 1 for concept definitions). 
Structural Thresholds. Structural thresholds are based on changes in relative species and growth form composition, spatial distribution of vegetation and bare soil, and the presence of invasive species (e.g., Friedel 1991; Laycock 1991; Scheffer et al. 2001; Stringham et al. 2003) (Table 1). This component of thresholds has received the greatest attention because it is most easily observed and quantified and it often serves as a precursor to the development of functional thresholds (see next section). Grassland and savanna conversion to shrubland or woodland and steppe conversion to exotic herbaceous annuals are the two most widely occurring structural thresholds on North American rangelands (e.g., Buffington and Herbel 1965; Mack 1981; Anderson and Inouye 2001; Bestelmeyer et al. 2004).

Functional redundancy among species has been recognized as an important component of ecosystem resilience (Walker 1995; Naeem 1998; Elmqvist et al. 2003). Redundancy describes the occurrence of ecological overlap among species to provide a margin of safety for ecosystem function and thereby maintain ecosystem resilience (Walker 1995). Redundancy allows for functional compensation based on the presence of several species within specific functional groups that are variously affected by disturbances (i.e., species possess similar function, but unique responses to disturbances) (Symstad et al. 1998; O'Connor et al. 2001; Foster et al. 2004). No such compensation is possible when functional groups are comprised of only one or very few species because species replacement is unlikely to occur in response to disturbance (Walker 1995). Classification of species redundancy within important functional plant groups may provide a viable means to identify the relative resilience of various rangeland ecosystems.

Functional Thresholds. Functional thresholds describe modifications of various ecological processes that maintain ecosystem function and resilience (Table 1). The prevailing interpretation is that function is determined by the extent to which water and nutrients are retained within ecosystems (Whisenant 1999; Ludwig et al. 2000; van de Kopel et al. 2002; Belnap et al. 2005). Therefore, ecosystems that lose a large proportion of their resource inputs through runoff and soil erosion will show impaired function, including reduced productivity, nutrient pools, and rates of nutrient cycling (Schlesinger et al. 1990; Davenport et al. 1998). Aboveground primary production may even decrease per unit rainfall (i.e., rainfall-use efficiency) as vegetation and soil structure become increasingly modified (Le Houérou 1984; Snyman 1998, 1999; Wiegand et al. 2004).

Functional thresholds are exceeded when the amount and spatial distribution of ground cover is sufficiently modified to accelerate soil, nutrient, and water movement across the landscape (Davenport et al. 1998; Ludwig et al. 2000; Cammeraat 2004; van de Koppel and Rietkerk 2004). This occurs when the mosaic of vegetated (run-on) and bare ground (run-off) patches is modified to the extent that the landscape is no longer able to retain resources (e.g., number and connectivity of run-off patches has exceeded a critical value) (Davenport et al. 1998). The run-off patches begin to coalesce to allow water and soil to move across the landscape and enter adjacent streams and tributaries. Increasing run-off and soil erosion feedback to reduce infiltration and increase evaporation which further reduces water availability for plant growth and increases the amount of bare ground (Schlesinger et al. 1990; Davenport et al. 1998; Ludwig et al. 2005). Initial occurrence and expression of functional thresholds is influenced by numerous variables including climate, geomorphology, soil characteristics, and land use patterns (Davenport et al. 1998).

Nutrient redistribution from a fine to a coarse scale of heterogeneity is promoted by woody plant invasion as shrubs concentrate resources beneath their canopies (Schlesinger et al. 1990; Ludwig et al. 2000; Rietkerk et al. 2004). Nutrient redistribution into patches may intensify grazing on smaller portions of the landscape to promote further nutrient redistribution and their potential loss from the site (van de Koppel et al. 2002). This interpretation of resource redistribution indicates that modifications to ecosystem function can be inferred from several spatial attributes of community structure (Davenport et al. 1998; Ludwig et al. 2000, 2005). The site conservation threshold described by the SRM Task Group (1995) approximates a functional threshold because it is based upon the presence of a sufficient type and amount of vegetative cover to prevent accelerated soil erosion.

Feedback Mechanisms. Feedback mechanisms represent ecological processes that reinforce (e.g., negative) or degrade (e.g., positive) the resilience of stable states. A feedback switch occurs when there is a shift from a dominance of negative feedbacks to a dominance of positive feedbacks to reduce resilience of a pre-threshold state (Wilson and Agnew 1992; Scheffer and Carpenter 2003; Peters et al. 2004; Mayer and Rietkerk 2004). The rate at which the feedback switch occurs will establish the degree of non-linearity or discontinuity characteristic of a threshold. A conversion from pre- to postthreshold states will follow this feedback switch, but it may occur over years or decades and it may proceed in a continuous, discontinuous, or a combination of these two patterns (e.g., Watson et al. 1996; Walker and Meyers 2004). This interpretation emphasizes that threshold discontinuity is associated with occurrence of the feedback switch and not necessarily with the subsequent pattern of threshold progression.

The contribution of feedback mechanisms to threshold occurrence can be illustrated with an example of grassland conversion to a woodland stable state. Frequent fire and fire suppression represent triggers that initiate negative and positive feedbacks, respectively, for maintenance of the grassland state (Walker and Meyers 2004). Positive feedbacks associated with fire suppression include woody plant establishment and increasing woody cover, loss of herbaceous species, and nutrient redistribution that collectively reduce the amount and continuity of fine fuel loads. These positive feedbacks collectively force the transition from grassland to woodland states by interrupting the frequent fire regime. In contrast, negative feedbacks associated with frequent fire regimes include maintenance of grassland composition and productivity and fine scale nutrient heterogeneity that produce large and continuously distributed fine fuel loads to maintain the grassland state (Knapp et al. 1999; Briggs et al. 2005). 


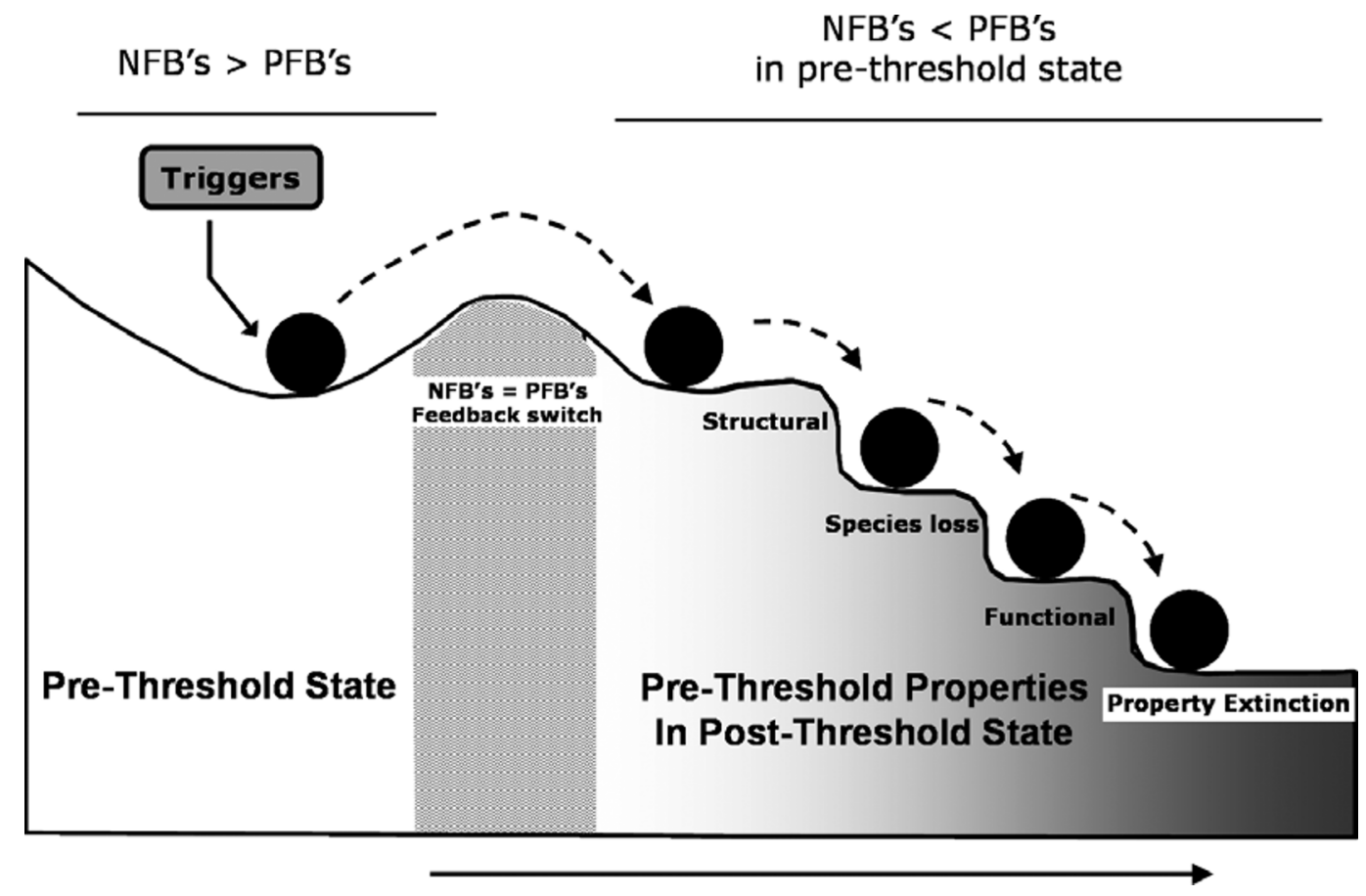

Figure 3. Schematic illustrating threshold progression from a pre-threshold state to residual pre-threshold properties that persist within the postthreshold state after a threshold has been exceeded on a site. Four threshold categories identify critical ecological processes that contribute to the successive loss of residual pre-threshold properties, as indicated by increased shading from left to right, and identify ecological benchmarks that describe the extent of threshold progression and the potential for threshold reversal. A threshold is initially surpassed when feedbacks switch from negative (NFB) to positive (PFB) to exceed the resilience limits of the pre-threshold state. Resilience of the post-threshold state (not shown) will increase as the residual pre-threshold properties progresses through these successive threshold categories (see Table 1 for concept definitions).

\section{Threshold Categories}

Thresholds could be more effectively assessed and applied, if distinct categories were evident within the progression of threshold development. These categories may serve as ecological benchmarks to describe the extent of threshold progression, increase insight into the processes and feedbacks reducing resilience of pre-threshold states, and promote development of operational threshold descriptions and applications. Brown and others (1999) have previously organized thresholds into ecological, management, and economic components; Walker and Meyers (2004) have organized information for threshold application to broad social-ecological systems; and Peters and others (2004) have proposed a multi-scale model of threshold development. Our interpretation emphasizes the successive occurrence of major ecological processes that reduce resilience of pre-threshold states to reinforce threshold progression on individual ecological sites.

Structural, species loss, functional, and property extinction threshold categories are described to illustrate the development and application of this concept (Fig. 3, Table 1). These categories apply to the progression of a single threshold and specifically reference the fate of the pre-threshold state after a threshold has been crossed. In other words, the pre-threshold state does not immediately become extinct when a threshold is crossed and a post-threshold state begins to dominate the site. For example, residual properties of a grassland community may exist for decades following woodland encroachment (Dye et al. 1995; Naumburg et al. 2001) and it is these residual ecosystem properties that provide the potential for grassland recovery following woody plant removal (e.g., threshold reversal). Properties of pre-threshold states that persist after thresholds have been crossed to alternative states can be termed residual pre-threshold properties. Pre-threshold properties may eventually be eliminated from post-threshold states on individual sites after extended periods of time.

Threshold categories are anticipated to occur successively so they may not necessarily be distinct and substantial overlap may occur among them. These categories may be expressed in a very similar manner to that of threshold progression, e.g., continuous or discontinuous, or a combination of these two patterns (Fig. 3). This progression of threshold categories generally parallels the conceptual model of ecosystem degradation (e.g., Milton et al. 1994; Whisenant 1999), but it is specifically applied to residual properties of the pre-threshold state that persist in the post-threshold state. All potential threshold categories may not be expressed because threshold progression may stabilize prior to extinction of all residual prethreshold properties within the post-threshold state. The postthreshold state becomes increasingly dominant and threshold reversal becomes less likely on sites as the residual prethreshold properties progresses through these various threshold categories.

Structural Category. The structural threshold category is associated with structural thresholds because it is based exclusively on modifications to relative species composition and 
patterns of species distribution. However, this category, as well as the other threshold categories, is applied to the pre-threshold state of a specific threshold progression (Fig. 3). It is assumed that insufficient time has passed within threshold progression for substantial modification of ecosystem processes to have occurred, even though the switch from negative to positive feedbacks has previously taken place. In most cases, removal of the dominant species from the post-threshold state is anticipated to reverse the threshold. This category possesses the greatest managerial significance because it is most easily quantified and it identifies the initial stage of threshold progression following the occurrence of a threshold. This threshold category is similar to the current application of thresholds, but it does not possess a temporal reference to managerial options (e.g., Friedel 1991).

Species Loss Category. This threshold category is also associated with structural thresholds and it defines the point of threshold progression where insufficient species richness and genetic diversity remain to re-establish the pre-threshold state even when dominant species of the post-threshold state are removed by management prescriptions (Fig. 3). Species reintroductions are required once this threshold category has been surpassed because regional species extinctions have occurred. It is assumed that ecosystem function will still support establishment and growth of the pre-threshold dominants, if propogules are introduced to the site. Propogule availability and dispersal limitations represent important constraints on species recovery following disturbance (Foster and Gross 1997; Kirkman et al. 2004).

Unfortunately, the adverse effects of threshold progression on species richness and genetic diversity have been largely unexplored. Minimal experimental evidence exists to identify the rate, extent, or mechanism of grassland species loss or recovery following woody plant encroachment or removal, respectively (but see Dye et al. 1995; Brockway et al. 2002; Tiedemann and Klemmmedson 2004). However, dense woodland canopies can be envisioned to suppress grassland populations by several interrelated mechanisms, including a decrease in photosynthetically active radiation, competition for soil water and nutrients, potential allelopathic effects, and the modification of physical and chemical soil properties (Scholes and Archer 1997; Naumburg et al. 2001). The reduction in species richness and productivity of perennial grasses beneath the dense canopy and litter layer of mature Juniper (Juniperus spp.) communities is a frequently cited example of this phenomenon (Dye et al. 1995; Briggs et al. 2002). Grassland encroachment by J. virginiana may greatly modify species composition and suppress grassland recovery within as little as 20 years (Gehring and Bragg 1992). The resource competition-fire cycle associated with exotic grass invasion also produces propogule and dispersal limitations for native perennial grass and shrub dominants of the pre-threshold state (D’Antonio and Vitousek 1992; Knapp 1996).

Functional Category. The functional threshold category is associated with functional thresholds and describes the point of threshold progression where positive feedbacks have suffi- ciently progressed such that ecological processes will no longer support dominants of the pre-threshold state, even if dominants of the post-threshold state are removed (Fig. 3). Once this category has been exceeded, restoration procedures are required to reestablish ecological processes to enable dominants of the pre-threshold state to reoccupy the site (Whisenant 1999; Stringham et al. 2003). This category is similar to the restoration threshold proposed by Suding and others (2004) that describes barriers to restoring degraded ecosystems. In these cases, costly, large scale restoration programs will be required to restore ecosystem function and resilience of the pre-threshold state.

Property Extinction Category. This threshold category defines the point where residual pre-threshold properties have become extinct and the post-threshold state completely dominates the site (Fig. 3). Ecosystem structure and function are entirely determined by the post-threshold state at this point of threshold progression. It is uncertain how often this category may occur and it may often be associated with abiotic site modification. Occurrence of this threshold category determines that the potential for threshold reversal and site reoccupation by the pre-threshold state has been lost.

\section{Threshold Trajectories}

Threshold trajectories describe the developmental pathway of post-threshold states once triggers have induced a feedback switch and a threshold has been surpassed. Threshold trajectories and their associated post-threshold states are strongly influenced by regional climates that influence species and growth form distribution and primary productivity (Havstad and Herrick 2003). Consequently, these trajectories may produce a continuum of potential post-threshold states, but the majority of them may be organized into four broad states to simplify ecological interpretation and management application (Fig. 4). Each of these broad post-threshold states will express varying degrees of dissimilarity in response to variation in climate, topography, soils, and prior land use.

These four broad post-threshold states are envisioned to be arrayed along three sets of ecosystem controls. The first set of controls is associated with autogenic succession from a disturbance community toward the climatic climax community (Briske et al. 2005) or ecological degradation away from the climax community (e.g., Milton et al. 1994) (Fig. 4). The second set of controls is characterized by water and nutrient accumulation or redistribution and the potential for loss from ecosystems. The third set of ecosystem controls is associated with the relative strength of biotic and abiotic processes that drive threshold trajectories to establish specific post-threshold states (Davenport et al. 1998; Whisenant 1999; Peters et al. 2004). This set of controls is associated with a reduction in plant cover and productivity and a corresponding increase in bare ground and soil erosion. Threshold trajectories characterized by unique combinations of ecosystems controls are anticipated to possess unique rates and patterns of threshold progression so that their explicit recognition will provide greater insight into threshold assessment and application. 

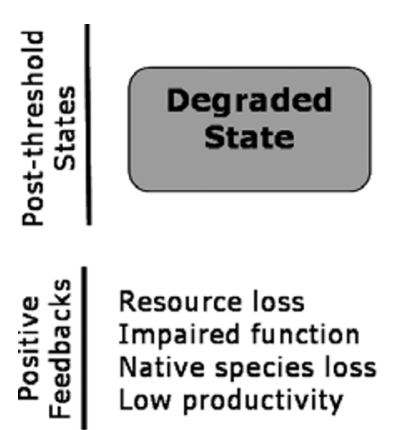

Species introduction Intense competition Native species loss Modified function
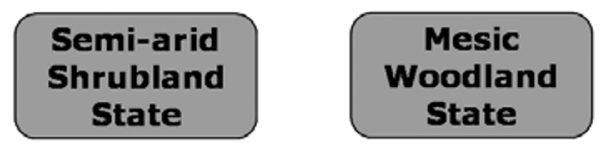

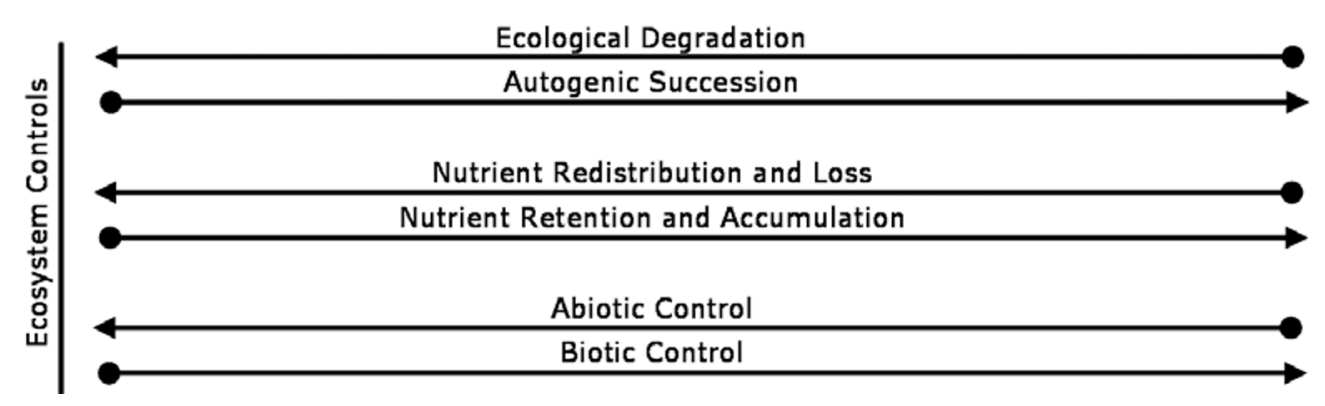

Figure 4. Threshold trajectories describe the developmental pathway that post-threshold states may take after a threshold has been surpassed. These trajectories may produce a continuum of post-threshold states, but the majority of them can be placed into four broad states, including mesic woodland, semiarid shrubland, invasive exotics, and severely degraded states. Each of these post-threshold states is associated with a unique set of positive feedbacks and supported by various environmental controls that establish the attributes of the respective post-threshold state (see Table 1 for concept definitions).

\section{MANAGEMENT APPLICATIONS}

This threshold framework identifies both critical ecological processes and management implications associated with threshold occurrence and progression. It evaluates ecological thresholds within a broad scope of land management applications, including restoration ecology and conservation biology, by linking threshold occurrence with ecological processes (e.g., Suding et al. 2004; Lindenmayer and Luck 2005).

Threshold progression is initiated by triggers that represent specific events or disturbances capable of shifting feedbacks from negative to positive to reduce resilience of pre-threshold states and promote development of post-threshold states. Threshold categories can be used to identify the extent of threshold progression and to assess the potential for threshold reversibility. The ability to define the chronological occurrence of these threshold categories will further increase their interpretive value for land management (e.g., Valone et al. 2002; Heisler et al. 2003; Asner et al. 2003). Threshold trajectories describe the developmental pathway of post-threshold states once a threshold has occurred and the majority of them can be organized into four broad alternative states.

This framework lends itself to management application by interpreting thresholds as a series of probabilities that determine their initiation, progression, and potential reversibility (Fig. 5). A probabilistic interpretation was selected because the recognized variation and complexity of thresholds precludes complete reliance on a process-based interpretation for the foreseeable future. Ecological processes have proven difficult to quantify rapidly and cost-effectively over extensive land areas and this constraint has impeded more rapid deployment of the rangeland health procedure (Pyke et al. 2002). A probabilitybased interpretation of threshold development will draw on a combination of ecological knowledge and management experience. Consequently, a probability-based and processbased interpretation of thresholds should not be viewed as being mutually exclusive because threshold assessment and prediction will improve with an increase in our understanding of threshold processes. Several modeling constructs currently exist, including Markovian and matrix models, to support probability-based projections of ecological thresholds (Caswell 2001; Wooton 2001). These models may prove to be useful research tools for investigating threshold behavior on rangelands (e.g., Hemstrom et al. 2002).

The first threshold probability addresses the occurrence of events or disturbances that will constitute a trigger to initiate threshold progression by inducing a switch from negative to positive feedbacks within the pre-threshold state (Fig. 5). This probability emphasizes the events or series of events that may initiate thresholds, rather than focusing on the existence of ecological indicators of threshold occurrence. This is the least understood of the three threshold probabilities and it emphasizes that greater attention must be focused on the identification of threshold triggers. The second threshold probability describes the trajectory that the post-threshold states may take once a threshold has been initiated (Fig. 5). This is perhaps the best understood probability because it is determined by regional climatic controls that constrain the distribution of plant species and growth forms and primary production. Several post-threshold states have been repeatedly expressed and consequently they are well recognized and documented (Fig. 4). The third probability describes the fate of the pre-threshold 


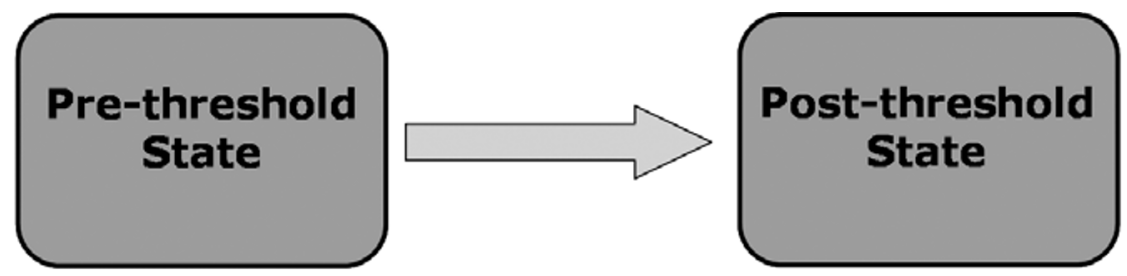

\begin{tabular}{|c|c|c|} 
Probability I & Probability II & Probability III \\
\hline Trigger Occurrence & Post-threshold State & Potential Reversibility
\end{tabular}

\section{Examples}

Frequent fire
Fire suppression
Drought
Intensive grazing
Trigger interactions

\author{
Mesic woodland \\ Semiarid shrubland \\ Exotic Species \\ Degraded State
}

\author{
Structural \\ Species loss \\ Functional \\ Extinction
}

\begin{abstract}
Probability I: $\quad$ Trigger will occur to initiate threshold progression; probabilities can be developed for various triggers or trigger combinations.
\end{abstract}

Probability II: Pathway of post-threshold trajectory after a threshold has been crossed; probabilities can be developed for various post-threshold states.

Probability III: Fate of pre-threshold state after a threshold has been crossed; probabilities can be developed for threshold reversal from various post-threshold states.

Figure 5. Operational thresholds are based on a probabilistic interpretation of 1) trigger occurrence, 2) trajectory of the post-threshold state, and 3) threshold reversibility. These probabilities are derived from previously described threshold components as identified beneath each of the three probabilities. A probabilistic interpretation of thresholds will enhance the consistency of threshold assessment and application by utilizing a combination of ecological knowledge and management experience.

state after a threshold has been exceeded and the post-threshold state begins to dominate an ecological site. This third probability emphasizes that thresholds exist at various stages of progression which provides valuable information for defining management and policy options regarding threshold reversibility (Fig. 5). For example, states that have crossed a threshold but still retain a majority of their pre-threshold species richness have a greater probability of reversal than states that have lost most of their species and supporting ecological functions. The residual species richness associated with pre-threshold properties may be directly observed in the post-threshold state or it may be determined following local removal of dominants within the post-threshold state to promote competitive release of the residual pre-threshold species (e.g., Díaz et al. 2003).

Threshold probabilities could be incorporated into both state-and-transition models and the associated ecological site descriptions (USDA 1997) to provide greater insight into threshold assessment and application. Probabilities defining trigger occurrence, the developmental pathway of post-threshold states, and the potential for threshold reversibility could be identified for each potential threshold on an ecological site. These probabilities will be derived from the best ecological knowledge and field experience available for each site and this information could be documented in a brief narrative. Threshold probabilities are specific to unique time periods of threshold progression which will reduce the ambiguity associated with temporal scale in the current application of thresholds and state-and-transition models. Threshold probabilities may be more accurately determined in mesic than in semiarid environments because the series of events within a threshold progression may occur much more rapidly (Briggs et al. 2005; Buonopane et al. 2005).

The highly conceptual nature and recent adoption of ecological thresholds has provided minimal insight into procedures necessary to support their application for land management. Consequently, the validity and effectiveness of ecological threshold for land management has yet to be fully explored and defined (e.g., Lindenmayer and Luck 2005; Groffman et al. 2006). The intent of this synthesis is to promote the process of threshold definition and evaluation by providing a framework that will enable rangeland professionals to incorporate existing ecological knowledge and management experience into threshold assessment and application. If ecological thresholds are to become a focal point for rangeland ecology and management, rangeland professionals must accept responsibility for their conceptual development, ecological validity, and managerial effectiveness.

\section{ACKNOWLEDGMENTS}

Participants in various NRCS rangeland ecology short courses provided DDB and FES with valuable context and encouragement for the development of this synthesis. The Texas and Oklahoma Agricultural Experiment Stations provided financial support to the authors during manuscript preparation. We wish to thank K. Havstad, P. Hiernaux, 1 
anonymous reviewer and the associate editor, David Tongway, for their contributions to this manuscript.

\section{LITERATURE CITED}

Anderson, J. E., And R. S. Inouye. 2001. Landscape-scale changes in plant species abundance and biodiversity of a sagebrush steppe over 45 years. Ecological Monographs 71:531-556.

Archer, S., T. W. Boutton, and K. A. HibBard. 2001. Trees in grasslands: biogeochemical consequences of woody plant expansion. In: E. D. Schulze, S. P. Harrison, M. Heimann, E. A. Holland, J. Lloyd, I. C. Prentice, and D. Schimel [EDS.]. Global biogeochemical cycles in the climate system. San Diego, CA: Academic Press. p 115-137.

Asner, G. P., S. Archer, R. F. Hughes, R. J. Ansley, and C. A. Wessman. 2003. Net changes in regional woody vegetation cover and carbon storage in Texas drylands, 1937-1999. Global Change Biology 9:316-335.

Austin, M. P., AND 0. Williams. 1988. Influence of climate and community composition on the population demography of pasture species in semi-arid Australia. Vegetatio 77:43-49.

Beisner, B. E., D. T. Haydon, and K. Cuddington. 2003. Alternative stable states in ecology. Frontiers in Ecology and the Environment 1:376-382.

Belnap, J., J. R. Welter, N. B. Grimm, N. Barger, and J. A. Ludwig. 2005. Linkages between microbial and hydrological processes in arid and semiarid watersheds. Ecology 86:298-307.

Bestelmeyer, B. T., J. R. Brown, K. M. Havstad, R. Alexander, G. Chavez, and J. E. HERRICK. 2003. Development and use of state-and-transition models for rangelands. Journal of Range Management 56:114-126.

Bestelmeyer, B. T., J. E. Herrick, J. R. Brown, D. A. Trujillo, and K. M. Havstad. 2004. Land management in the American southwest: a state-and-transition approach to ecosystem complexity. Environmental Management 34:38-51.

Bond, W. J., AND B. W. van Wilgen. 1996. Fire and plants. New York, NY: Chapman \& Hall. $263 p$.

Breshears, D. D., N. S. Cobb, P. M. Rich, K. P. Price, C. D. Allen, R. G. Balice, W. H. Romme, J. H. Kastens, M. L. Floyd, J. Belnap, J. J. Anderson, O. B. Myers, and C. W. MEYER. 2005. Regional vegetation die-off in response to global-change-type drought. Proceedings National Academy of Science 102:15144-15148.

Briggs, J. M., G. A. HoCH, AND L. C. Johnson. 2002. Assessing the rate, mechanisms, and consequences of the conversion of tallgrass prairie to Juniperus virginiana forest. Ecosystems 5:578-586.

Briggs, J. M., A. K. Knapp, J. M. Blair, J. L. Heisler, G. A. Hoch, M. S. Lett, and J. K. McCarron. 2005. An ecosystem in transition: causes and consequences of the conversion of mesic grassland to shrubland. BioScience 55:243-254.

Briske, D. D., S. D. Fuhlendorf, and F. E. Smeins. 2003. Vegetation dynamics on rangelands: a critique of the current paradigms. Journal of Applied Ecology 40:601-614.

Briske, D. D., S. D. Fuhlendorf, and F. E. Smeins. 2005. State-and-transition models, thresholds, and rangeland health: a synthesis of ecological concepts and perspectives. Rangeland Ecology and Management 58:1-10.

Brockway, D. G., R. G. Gatewood, and R. B. Paris. 2002. Restoring grassland savannas from degraded pinyon-juniper woodlands: effects of mechanical overstory reduction and slash treatment alternatives. Journal of Environmental Management 64:179-197.

Brown, J. R., AND S. ARCHER. 1999. Shrub invasion of grasslands: recruitment is continuous and not regulated by herbaceous density or biomass. Ecology 80:2385-2396.

Brown, J. R., J. HerRick, AND D. PricE. 1999. Managing low-output agroecosystems sustainably: the importance of ecological thresholds. Canadian Journal of Forest Research 29:1112-1119.

Buffington, L. D., And C. H. Herbel. 1965. Vegetation changes on a semidesert grassland range from 1958 to 1963. Ecological Monographs 35:139-164.

Buonopane, M., L. F. Huenneke, and M. Remmenga. 2005. Community response to removals of plant functional groups and species from a Chihuahuan shrubland. Oikos 110:67-80.

Cammeraat, E. L. H. 2004. Scale dependent thresholds in hydrological and erosion response of a semi-arid catchment in southeast Spain. Agriculture, Ecosystems and Environment. 104:317-332.
Caswell, H. 2001. Matrix population models: Construction, analysis, and interpretation. $2^{\text {nd }}$ ed. Sunderland, MA: Sinauer Associates Inc. $722 \mathrm{p}$.

Cingolani, A. M., I. Noy-MeiR, and S. Díaz. 2005. Grazing effects on rangeland diversity: a synthesis of contemporary models. Ecological Applications 15:757-773.

Cione, N. K., P. E. Padgett, And E. B. Allen. 2002. Restoration of a native shrubland impacted by exotic grasses, frequent fire, and nitrogen deposition in southern California. Restoration Ecology 10:376-384.

D’Antonio, C. M., And P. M. Vitousek. 1992. Biological invasions by exotic grasses, the grass/fire cycle, and global change. Annual Review of Ecology and Systematics 23:63-87.

Davenport, D. W., D. D. Breshears, B. P. Wilcox, and C. D. Allen. 1998. Viewpoint: Sustainability of piñon-juniper ecosystems-a unifying perspective of soil erosion thresholds. Journal of Range Management 51:231-240.

Davis, M. B. 1986. Climatic instability, time lags, and community disequilibrium. In: J. Diamond and T. J. Case [EDS.]. Community ecology. New York, NY: Harper \& Row Publishers. p 269-284.

Díaz, S., A. J. Symstad, F. S. Chapin III, D. A. Wardle, and L. F. Huenneke. 2003. Functional diversity revealed by removal experiments. Trends in Ecology and Evolution 18:140-146.

Dye, K. L., D. N. UeCKeRT, and S. G. Whisenant. 1995. Redberry-juniper-herbaceous understory interactions. Journal of Range Management 48:100-107.

ElLIS, J. E., AND D. M. SwIFt. 1988. Stability of African pastoral ecosystems: alternate paradigms and implications for development. Journal of Range Management 41:450-459.

Elmovist, T., C. Folke, M. Nyström, G. Peterson, J. Bengtsson, B. Walker, and J. Norberg. 2003. Response diversity, ecosystem change, and resilience. Frontiers in Ecology and the Environment 1:488-494.

Fensham, R. J., R. J. Falrfax, and S. R. Archer. 2005. Rainfall, land use and woody vegetation cover change in semi-arid Australian savanna. Journal of Ecology 93:596-606.

Folke, C., S. Carpenter, B. Walker, M. Scheffer, T. Elmovist, L. Gunderson, and C. S. HoLLING. 2004. Regime shifts, resilience, and biodiversity in ecosystem management. Annual Review of Ecology, Evolution and Systematics 35:557-581.

Foster, B. L., AND K. L. Gross. 1997. Partitioning the effects of plant biomass and litter on Andropogon gerardii in old-field vegetation. Ecology 78:2091-2104.

Foster, B. L., T. L. Dickson, C. A. Murphy, I. S. Karel, and V. H. Smith. 2004. Propagule pools mediate community assembly and diversity-ecosystem regulation along a grassland productivity gradient. Journal of Ecology 92:435-449.

Friedel, M. H. 1991. Range condition assessment and the concept of thresholds: a viewpoint. Journal of Range Management 44:422-426.

FunLENDORF, S. D., AND F. E. SmeIns. 1997. Long-term vegetation dynamics mediated by herbivores, weather and fire in a Juniperus-Quercus savanna. Journal of Vegetation Science 8:819-828.

Gehring, J. L., AND T. B. BragG. 1992. Changes in prairie vegetation under eastern red cedar (Juniperus virginiana L.) in an eastern Nebraska bluestem prairie. American Midland Naturalist 128:209-217.

Groffman, P. M., J. S. Baron, T. Blett, A. J. Gold, I. Goodman, L. H. Gunderson, B. M. Levinson, M. A. Palmer, H. W. Paerl, G. D. Peterson, N. L. Poff, D. W. Rejeski, J. F. Reynolds, M. G. Turner, K. C. Weathers, and J. Wiens. 2006. Ecological thresholds: the key to successful environmental management or an important concept with no practical application? Ecosystems 9:1-13.

GundERSON, L. H. 2000. Ecological resilience - in theory and application. Annual Review of Ecology and Systematics 31:425-439.

Havstad, K. M., and J. E. HeRRICK. 2003. Long-term ecological monitoring. Arid Land Research and Management 17:389-400.

HeISLER, J. L., J. M. BRiggs, AND A. K. KNAPP. 2003. Long-term patterns of shrub expansion in a C4-dominated grassland: fire frequency and the dynamics of shrub cover and abundance. American Journal of Botany 90:423-428.

Heisler, J. L., J. M. Briggs, A. K. Knapp, J. M. Blair, and A. Seery. 2004. Direct and indirect effects of fire on shrub density and aboveground productivity in a mesic grassland. Ecology 85:2245-2257.

Hemstrom, M. A., M. J. Wisdom, W. J. Hann, M. M. Rowland, B. C. Wales, and R. A. Gravenmier. 2002. Sagebrush-steppe vegetation dynamics and restora- 
tion potential in the interior Columbia Basin, USA. Conservation Biology 16: 1243-1255.

Higgins, P. A. T., M. D. Mastrandrea, and S. H. Schneider. 2002. Dynamics of climate and ecosystem coupling: abrupt changes and multiple equilibria. Philosophical Transactions Royal Society, London B 357:647-655.

Holuing, C. S. 1973. Resilience and stability of ecological systems. Annual Review of Ecology and Systematics 4:1-23.

Holuing, C. S. 1996. Surprise for science, resilience for ecosystems, and incentives for people. Ecological Applications 6:733-735.

HugGett, A. J. 2005. The concept and utility of 'ecological thresholds' in biodiversity conservation. Biological Conservation 124:301-310.

Illius, A. W., AND T. G. O'Connor. 1999. On the relevance of non-equilibrium concepts to arid and semi-arid grazing systems. Ecological Applications 9:798-813.

Kirkman, L. K., K. L. Coffey, R. J. Mitchell, and E. B. Moser. 2004. Ground cover recovery patterns and life-history traits: implications for restoration obstacles and opportunities in a species-rich savanna. Journal of Ecology 92:409-421.

KnAPP, P. A. 1996. Cheatgrass (Bromus tectorum $L$ ) dominance in the Great Basin desert; history, persistence, and influences to human activities. Global Environmental Change 6:37-52.

Knapp, A. K., J. M. Blair, J. M. Briggs, S. L. Collins, D. C. Hartnett, L. C. Johnson, and E. G. Towne. 1999. The keystone role of bison in the North American Tallgrass Prairie. BioScience 49:39-50.

LAYcock, W. A. 1991. Stable states and thresholds of range condition on North American rangelands: A viewpoint. Journal of Range Management 44: 427-433.

Le Houérou, H. N. 1984. Rain use efficiency: a unifying concept in arid-land ecology. Journal of Arid Environments 7:213-247.

Lindenmayer, D. B., AND G. LuCK. 2005. Synthesis: thresholds in conservation and management. Biological Conservation 124:351-354.

LudWig, J. A., J. A. Wiens, And D. J. Tongway. 2000. A scaling rule for landscape patches and how it applies to conserving soil resources in savannas. Ecosystems 3:84-97.

Ludwig, J. A., B. P. Wilcox, D. D. Breshears, D. J. Tongway, and A. C. Imeson. 2005. Vegetation patches and runoff-erosion as interacting ecohydrological processes in semiarid landscapes. Ecology 86:288-297.

Mack, R. N. 1981. Invasion of Bromus tectorum L. into western North America: an ecological chronicle. Agro-Ecosystems 7:145-165.

MACK, M. C., AND C. M. D'Antonio. 1998. Impacts of biological invasions on disturbance regimes. Trends in Ecology and Evolution 13:195-198.

MaY, R. M. 1977. Thresholds and breakpoints in ecosystems with a multiplicity of stable states. Nature 269:471-477.

Mayer, A. L., AND M. RietKerk. 2004. The dynamic regime concept for ecosystem management and restoration. BioScience 54:1013-1020.

Milton, S. J., W. R. J. Dean, M. A. du Plessis, and W. R. Siegrried. 1994. A conceptual model of arid rangeland degradation: the escalating cost of declining productivity. BioScience 44:70-76.

Muradian, R. 2001. Ecological thresholds: a survey. Ecological Economics 38: $7-24$.

Naeem, S. 1998. Species redundancy and ecosystem reliability. Conservation Biology 12:39-45.

Naumburg, E. L., E. DeWald, and T. E. Kolb. 2001. Shade responses of five grasses native to southwestern US Pinus ponderosa forests. Canadian Journal of Botany 79:1001-1009.

Nowak, C. L., R. S. Nowak, R. J. Tausch, and P. E. Wigand. 1994. Tree and shrub dynamics in northwestern Great Basin woodland and shrub steppe during the late-pleistocene and Holocene. American Journal of Botany 81:265-277.

O'Connor, T. G., L. M. Haines, And H. A. Snyman. 2001. Influence of precipitation and species composition on phytomass of a semi-arid African grassland. Journal of Ecology 89:850-860.

O'Connor, T. G., And P. W. Roux. 1995. Vegetation changes (1949-71) in a semiarid, grassy dwarf shrubland in the Karoo, South Africa: influence of rainfall variability and grazing by sheep. Journal of Applied Ecology 32:612-626.

Peters, D. P. C., R. A. Pielke, Sr., B. T. Bestelmeyer, C. D. Allen, S. Munson-McGee, and K. M. Havstad. 2004. Cross-scale interactions, nonlinearities, and forecasting catastrophic events. Proceedings National Academy of Science 101:15130-15135.

Peterson, G., C. R. Allen, and C. S. Holling. 1998. Ecological resilience, biodiversity, and scale. Ecosystems 1:6-18.

Prentice, I. C. 1986. Vegetation response to past climatic variation. Vegetatio 67:131-141.

Pyke, D. A., J. E. Herrick, P. Shaver, and M. Pellant. 2002. Rangeland health attributes and indicators for qualitative assessment. Journal of Range Management 55:584-597.

Rietkerk, M., S. C. DekKer, P. C. de Ruiter, and J. van de Koppel. 2004. Self-organized patchiness and catastrophic shifts in ecosystems. Science 305:1926-1929.

Scheffer, M., S. Carpenter, J. A. Foley, C. Folke and B. Walker. 2001. Catastrophic shifts in ecosystems. Nature 413:591-596.

Scheffer, M., and S. Carpenter. 2003. Catastrophic regime shifts in ecosystems: linking theory to observation. Trends in Ecology and Evolution 18:648-656.

Schlesinger, W. H., J. F. Reynolds, G. L. Cunningham, L. F. Huenneke, W. M. Jarrell, R. A. Virginia, and W. G. Whitford. 1990. Biological feedbacks in global desertification. Science 47:1043-1084.

Scholes, R. J., And S. R. ARCher. 1997. Tree-grass interactions in savannas. Annual Review of Ecology and Systematics 28:517-544.

Snyman, H. A. 1998. Dynamics and sustainable utilization of rangeland ecosystems in arid and semi-arid climates of southern Africa. Journal of Arid Environments 39:645-666.

Snyman, H. A. 1999. Short-term effects of soil water, defoliation and rangeland condition on productivity of a semi-arid rangeland in South Africa. Journal of Arid Environments 43:47-62.

SRM TASK Group (Society for Range Management Task Group on Unity in Concepts and Terminology Committee, Society for Range Management). 1995. New concepts for assessment of rangeland condition. Journal of Range Management 48:271-282.

Stringham, T. K., W. C. Krueger, and P. L. Shaver. 2003. State and transition modeling: an ecological process approach. Journal of Range Management 56:106-113.

Suding, K. N., K. L. Gross, and G. R. Houseman. 2004. Alternative states and positive feedbacks in restoration ecology. Trends in Ecology and Evolution 19:46-53.

Symstad, A. J., D. Tilman, J. Willson, and J. M. H. Knops. 1998. Species loss and ecosystem functioning: effects of species identify and community composition. Oikos 81:389-397.

Tausch, R. J., P. E. Wigand, and J. W. Burkhardt. 1993. Viewpoint: plant community thresholds, multiple steady states, and multiple successional pathways: legacy of the Quaternary? Journal of Range Management 46:439-447.

Tiedemann, A. R., AND J. 0. Klemmedson. 2004. Responses of desert grassland vegetation to mesquite removal and growth. Journal of Range Management $57: 455-465$.

USDA, NRCS. 1997. National range and pasture handbook. United States Department of Agriculture, Natural Resource Conservation Service, Grazing LandsTechnology Institute. 190-vi-NRPH, Washington D.C.

Van de Koppel, J., M. Rietkerk, F. van Langevelde, L. Kumar, C. A. Klausmeier, J. M. Fryxell, J. W. Hearne, J. van Andel, N. de Ridder, A. Skidmore, L. StroosniJder, AND H. H. T. PRins. 2002. Spatial heterogeneity and irreversible vegetation change in semiarid grazing systems. American Naturalist 159:209-218.

Van de Koppel, J., And M. RietKerk. 2004. Spatial interactions and resilience in arid ecosystems. American Naturalist 163:113-121.

Van Nes, E. H., and M. Scheffer. 2005. Implications of spatial heterogeneity for catastrophic regime shifts in ecosystems. Ecology 86:1797-1807.

Valone, T. J., M. Meyer, J. H. Brown, and R. M. Chew. 2002. Timescale of perennial grass recovery in desertified arid grasslands following livestock removal. Conservation Biology 16:995-1002.

WALKER, B. H. 1993. Rangeland ecology: understanding and managing change. Ambio 22:80-87.

WALKER, B. 1995. Conserving biological diversity through ecosystem resilience. Conservation Biology 9:747-752.

Walker, B., And J. A. Meyers. 2004. Thresholds in ecological and social-ecological systems: a developing data base. Ecology and Society 9(2):3. URL: http:// www.ecologyandsociety.org/vol9/iss2/art3. 
Watson, I. W., D. G. Burnside, And A. McR. Holm. 1996. Event-driven or continuous; which is the better model for managers? Australian Rangeland Journal 18:351-369.

Watson, I. W., M. Westoby, and A. McR. Holm. 1997. Demography of two shrub species from an arid grazed ecosystem in Western Australia 1983-93. Journal of Ecology 85:815-832.

Westoby, M., B. H. Walker, and I. Noy-MelR. 1989. Opportunistic management for rangelands not at equilibrium. Journal of Range Management 42:266-274.
WhISENANT, S. G. 1999. Repairing damaged wildlands: A process-oriented, landscape-scale approach. New York, NY: Cambridge University Press. 312 p.

Wiegand, T., H. A. Snyman, K. Kellner and J. M. Paruelo. 2004. Do grasslands have a memory?: modeling phytomass production of a semiarid South African grassland. Ecosystems 7:243-258.

Wilson, J. B., AND A. D. Q. Agnew. 1992. Positive-negative feedback switches in plant communities. Advances in Ecological Research 23:263-336.

Wootton, J. 2001. Prediction in complex communities: analysis of empirically derived Markov models. Ecology 82:580-598. 